\title{
Biomass growth response to spatial pattern of variable-retention harvesting in a northern Minnesota pine ecosystem
}

\author{
Brian J. Palik, ${ }^{1,5}$ Rebecca A. Montgomery, ${ }^{2}$ Peter B. Reich, ${ }^{2,3}$ and Suzanne B. Boyden ${ }^{4}$ \\ ${ }^{1}$ USDA Forest Service, Northern Research Station, 1831 Highway 169 East, Grand Rapids, Minnesota 55744 USA \\ ${ }^{2}$ Department of Forest Resources, University of Minnesota, 115 Green Hall, 1530 Cleveland Avenue North, \\ Saint Paul, Minnesota 55108 USA \\ ${ }^{3}$ Hawkesbury Institute for the Environment, University of Western Sydney, New South Wales 2753, Australia \\ ${ }^{4}$ Department of Biology, Clarion University, Clarion, Pennsylvania 16214 USA
}

Abstract. Variable-retention harvesting (VRH) is an approach for sustaining complex structure in managed forests. A criticism of VRH is that ecological benefits may come at a cost of reduced growth of regeneration, due to competition with residual trees. However, the spatial pattern of retention, i.e., dispersed or aggregated, in VRH systems can be manipulated to minimize suppression of regeneration, and resource limitation to regeneration might be mitigated by reduction of woody shrubs. Continued growth of the residual cohort will compensate for growth reduction of regeneration, although this may differ with retention pattern. We examined aboveground whole-stand biomass growth of trees in a VRH experiment in Pinus resinosa forest in Minnesota, USA. Treatments included dispersed retention, aggregated retention, and an uncut control, as well as a shrub treatment (reduced density or ambient). We addressed the following hypotheses: (1) biomass growth of a cohort of planted pine seedlings will be highest with aggregated rather than dispersed retention, (2) biomass growth of the planted seedlings will increase with shrub reduction, and (3) biomass growth of the residual overstory will be higher with dispersed rather than aggregated retention.

Aboveground biomass growth of the planted pines ranged from $0.4 \mathrm{~kg} \cdot \mathrm{ha}^{-1} \cdot \mathrm{yr}^{-1}$ in the overstory-control-ambient-shrub treatment to $23 \mathrm{~kg} \cdot \mathrm{ha}^{-1} \cdot \mathrm{yr}^{-1}$ in the aggregated-retentionshrub-reduction treatment. The difference between the control and the retention treatments was significant $(P<0.0001)$, but not between dispersed and aggregated retention $(P=0.97)$. Thus, our first hypothesis was not supported. In all treatments, biomass growth was significantly higher $(>100 \%$ increase) with shrub reduction $(P=0.001)$, supporting our second hypothesis. Biomass growth of residual trees ranged from $2404 \mathrm{~kg} \cdot \mathrm{ha}^{-1} \cdot \mathrm{yr}^{-1}$ in the uncutcontrol-ambient-shrub treatment to $1043 \mathrm{~kg} \cdot \mathrm{ha}^{-1} \cdot \mathrm{yr}^{-1}$ in the aggregated-retention-shrubreduction treatment. Differences were significant between the control and retention treatments $(P=0.003)$, and marginally higher with dispersed vs. aggregated retention $(P=0.09)$, lending support to our third hypothesis. Our results suggest that managers have flexibility in application of VRH and can expect similar stand-level biomass growth of planted regeneration regardless of retention pattern, but somewhat higher stand-level biomass growth of retained trees with dispersed retention.

Key words: aggregated retention; biomass growth; dispersed retention; Pinus resinosa; planted seedlings; residual trees; tree regeneration; variable-retention harvesting.

\section{INTRODUCTION}

Silvicultural systems that create similar structural outcomes as those that follow from natural disturbance have gained wide acceptance as an approach for managing forests to sustain or restore species diversity and structural complexity (Franklin et al. 2002, Drever et al. 2006). A common feature of these management approaches is the recognition that post-natural disturbance stands display more complex structure and within-stand spatial heterogeneity than typically occurs

Manuscript received 20 June 2013; revised 3 December 2013; accepted 16 April 2014. Corresponding Editor: J. B. Bradford.

${ }^{5}$ E-mail: bpalik@fs.fed.us after traditional commercial timber harvests (Lindenmayer and Franklin 2002). Even natural stand-replacing disturbances leave a spatially heterogeneous landscape that includes a rich array of biological legacies, especially large living trees and deadwood, which provide continuity of functions in the new stand (Franklin et al. 2000, Swanson et al. 2011).

Variable-retention harvesting (VRH), in which live trees and other structural legacies are retained during regeneration harvests, has evolved as an approach for sustaining or restoring more complex forest stands (Beese et al. 2003, Gustafsson et al. 2012, Lindenmayer et al. 2012, Scott et al. 2013). Retained trees in VRH stands serve several ecological functions during early 
forest development, including supplying energy and nutrients to soil organisms, modifying microclimate, providing habitat for recolonizing organisms by structurally enriching the new stand, and improving connectivity in the landscape for some organisms (Franklin et al. 2007, Baker et al. 2013).

A criticism of VRH systems, when advocated for use in commercial forests, is that ecological benefits may come at a cost of reduced growth of the regenerating cohort of trees, due to competition with residual trees (Rose and Muir 1997, Zenner et al. 1998, Gradowski et al. 2010, Newsome et al. 2010, Scott et al. 2013). This may be particularly true for species intolerant of low resource environments. Suppression of regeneration of intolerant species under even moderate amounts of overstory competition has been noted in a variety of ecosystems and is not unique to VRH systems (e.g., Tesch and Korpela 1993, Buckley et al. 1998, Dignan et al. 1998, Huffman et al. 1999). However, unlike most traditional silvicultural approaches, which seek to create rather homogeneous structural and resource environments across a stand, VRH systems seek to create heterogeneous conditions by varying the spatial pattern of retention (e.g., dispersed or aggregated [Franklin et al. 2007]) so as to achieve different ecosystem outcomes (Franklin et al. 1997, Aubry et al. 2009, Baker et al. 2013). This may include influencing resource availability to the understory (Palik et al. 2003) such that uniform, stand-wide growth suppression of tree regeneration is not necessarily a forgone conclusion (Palik et al. 1997).

To illustrate, with dispersed retention, most regeneration neighborhoods are in relatively close proximity to overstory trees, where growth of target plants is restricted to some degree due to resource competition (Palik et al. 2003, Boyden et al. 2012). In contrast, with aggregated retention, a larger proportion of regeneration neighborhoods should be farther away from overstory trees, where resource competition is lower. In short, in aggregated retention, extra resources available to some regenerating trees should increase their growth more than reduced resources constrain growth of those individuals under greater than average crowding. Consequently, when abundance of overstory competitors is held constant, stand-wide growth of regeneration should be higher with aggregated retention than with dispersed retention (assuming this regeneration is widely distributed across the stand), as others have predicted (Franklin et al. 1997, Coates 2000). This suggests that growth reductions of a regenerating cohort of trees can be mitigated to some degree by manipulating the spatial pattern of overstory retention.

The growth response of a new cohort of trees in VRH stands is also likely to be influenced by competition with pre-established understory vegetation, especially woody shrubs, which may preempt resources liberated as overstory competition decreases (Montgomery et al. 2010). Thus, the extent to which pre-established shrubs can be prevented from preempting resources in $\mathrm{VRH}$ stands may have profound effects on the growth of new tree seedlings (Dovciak et al. 2003, Weyenberg et al. 2004), such that growth reductions of the regeneration cohort with retention can be mitigated to some extent.

Finally, the focus of growth research in VRH systems has usually been on the new cohort of trees (Palik et al. 2003, Aubry et al. 2004, Mitchell et al. 2007, Scott et al. 2013, Urgenson et al. 2013), with much less research on growth responses of the residual cohort of trees. Standwide growth increases of the residual cohort should more than compensate for reductions in growth of the new cohort. For example, diameter growth of Pinus strobus (eastern white pine) in retention stands in Ontario, Canada increased $68 \%$ above uncut controls, reflecting a substantial enhanced contribution of these trees to total stand growth in the retention stand (Bebber et al. 2004).

The growth response of the residual overstory cohort also may be influenced by spatial pattern of retention through effects on resource acquisition. With dispersed retention there should be limited inter-tree shading and moisture competition, and therefore less light and water limitation among residual trees (Boyden et al. 2012). In contrast, aggregated retention leaves groups of trees in close proximity to each other, maintaining patterns of inter-tree competition within portions of the group (Boyden et al. 2012). Subdominant trees will be at a disadvantage at acquiring light and, consequently, growth of the residual cohort, on a per area basis, should be lower with aggregated retention. Similarly, in systems that are $\mathrm{N}$-limited, dispersed retention should optimize growth of the residual overstory because more $\mathrm{N}$ will be preempted by this cohort compared with aggregated retention (Palik et al. 2003). Some empirical research supports this contrast, at least at the individual tree level. For instance, volume growth of residual trees in Pseudotsuga menziesii (Douglas-fir)-dominated forests differed with spatial pattern of retention, such that trees in dispersed treatments had significantly greater growth than those in aggregated treatments (Maguire et al. 2006).

Here we examined stand-level responses of aboveground biomass growth of residual trees and the new cohort of planted seedlings to spatial pattern of overstory retention in VRH stands. We also examined the role of pre-established woody shrubs at mediating regeneration growth responses to spatial pattern of retention. We addressed the following hypotheses: (1) stand-level aboveground biomass growth of a new cohort of planted seedlings will be highest with aggregated rather than dispersed retention, even when holding residual overstory basal area constant immediately post-harvest; (2) biomass growth of the new cohort of planted seedlings will increase with woody shrub reduction, partially compensating for growth reductions that occur with overstory retention; and (3) aboveground biomass growth of the residual overstory will be greatest with dispersed retention, compared to aggre- 
gated retention. We addressed our objective and hypotheses using an operational-scale replicated experiment in a Pinus resinosa (red pine) ecosystem in Minnesota, USA. The experiment includes both dispersed and aggregated spatial patterns of retention, as well as reduction of pre-established woody shrubs. Research on natural disturbance dynamics in Pinus resinosa ecosystems provides justification for use of a retention harvesting approach, combined with understory shrub control, to emulate the structural outcomes of natural disturbance. Several recent studies document the existence of structurally complex, two- and threecohort old-growth forests that developed in response to heavy, but partial, canopy disturbances from fire and perhaps wind and that left substantial numbers of residual trees in various spatial patterns (Drobyshev et al. 2008, Fraver and Palik 2012). Moreover, research on fire regimes in Pinus resinosa forests describe the importance of frequent surface fires (5-50 years) for controlling understory woody encroachment of shrubs and hardwoods and preparing seedbeds for pines (Frissell 1973, Heinselman 1999).

\section{Methods}

\section{Study area}

We conducted our experiment on the Chippewa National Forest in north-central Minnesota, USA. The site has a cold-temperate climate with mean annual temperature of $4^{\circ} \mathrm{C}$ and mean annual precipitation of 70 $\mathrm{cm}$. The study area contains outwash and ice contact landforms characterized by deep-sand parent materials. Soils are excessively to well-drained, nutrient-poor, loamy sands. This ecosystem is dominated by Pinus resinosa in the overstory (90\% of basal area), with smaller amounts of Pinus strobus (eastern white pine), Pinus banksiana (jack pine), Acer rubrum (red maple), Populus tremuloides (trembling aspen), Populus grandidentata (bigtooth aspen), Betula papyrifera (paper birch), Abies balsamea (balsam fir), Picea glauca (white spruce), Quercus rubra (northern red oak), and Quercus macrocarpa (bur oak). The understory is dominated by Corylus cornuta (beaked hazel) and Amelanchier spp. (serviceberry). Stands were around 85 years old at the time of treatment, broadly even-aged, averaging $27 \mathrm{~m}$ in height of dominant Pinus resinosa, and naturally regenerated after early 20th-century logging and wildfires.

\section{Experimental design}

Our experiment was implemented as a randomizedblock, split-plot design replicated four times, with three main-plot retention treatments and two within-plot woody shrub control treatments. We randomly selected four blocks from a population of eight within the greater study landscape. Each block consisted of four $\sim 16$-ha stands and assignment of stands to blocks was based solely on geographic location. Overstory retention treatments were assigned randomly to a block as follows
(Fig. 1): control (no overstory removal), dispersed retention, and aggregated retention achieved by cutting 0.30-ha gaps.

Note that there was a fourth treatment installed in each block that consisted of aggregated retention achieved by cutting 0.10 -ha gaps. This treatment is omitted from the current study because the residual basal area in this treatment was somewhat higher after harvest than treatments 2 and 3, which added another influencing variable beyond spatial pattern, making interpretation of response in the current study difficult. There is a growing portfolio of research from this experimental setting, including work on songbird communities (Atwell et al. 2008), seedling disease and mortality (Ostry et al. 2012), tree physiological processes (Powers et al. 2008, 2009a, b, 2010, 2011), early survival and growth of seedlings in gaps (Peck et al. 2012), individual seedling mortality and diameter and height growth (Montgomery et al. 2013), and, importantly for our purpose, resource availability (Montgomery et al. 2010, Boyden et al. 2012).

Stands were cut in winter 2002-2003 to a residual basal area of $17 \mathrm{~m}^{2} /$ ha. In the dispersed retention treatment, preference was given to retaining large red pines, and large individuals of other species when they occurred (other species contributed $10 \%$ of total basal area). We did not include a clearcut treatment in our study because there are good data on growth of regeneration in clearcuts for this forest type (e.g., Blake and Yeatman 1989, Weber et al. 1995, Pitt et al. 2000) and, importantly, the cooperating National Forest no longer uses clearcutting in mixed-pine forests. However, for comparative purposes, we do summarize responses from data collected in the middle of the 0.3-ha openings that were part of the aggregated treatment (see Data analysis).

In each block, overstory treatment was factored with a woody shrub treatment. On one-half of each stand, shrub stems were manually cut with a brush cutter in mid- to late spring (reduction). Shrubs were left intact (ambient) on the other half of treatment stand. This treatment targeted woody and semi-woody shrub species, mostly Corylus and Rubus (raspberry), as well as prolific sprouters such as two Populus species. The shrub control treatment was applied annually from 2002 through 2007.

In spring 2003, each treatment stand was hand planted with equal numbers of 2-yr-old nursery-grown bare-root Pinus resinosa, $P$. strobus, and $P$. banksiana seedlings. These species are native components in mixedpine ecosystems in the region and differ in shade tolerance (Burns and Honkala 1990), from very intolerant ( $P$. banksiana), to intolerant $(P$. resinosa), to mid-tolerant ( $P$. strobus). Average planting density was around 1200 trees/ha divided equally among the three species. This planting density was about $50 \%$ of the typical planting density for commercial forests in the region. The pine planting was done to augment natural 
a
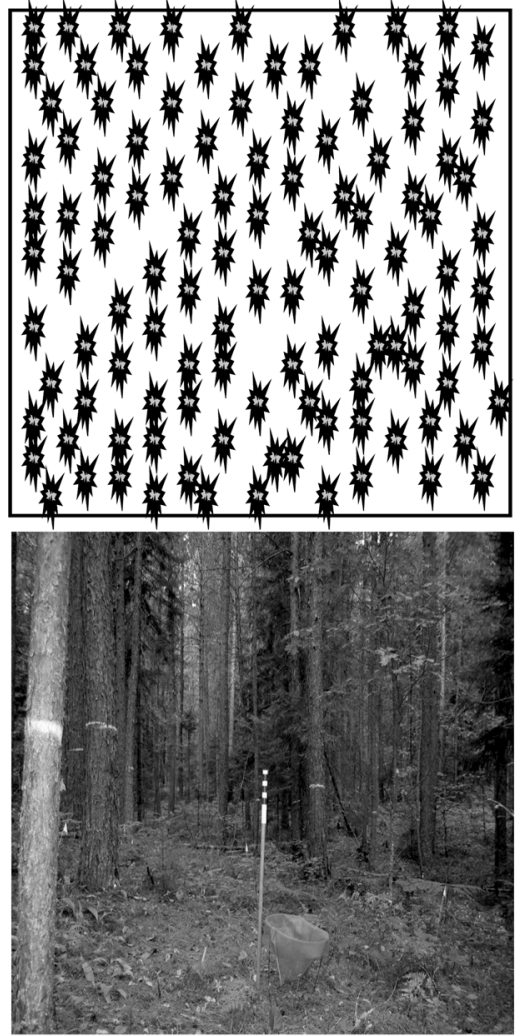

b
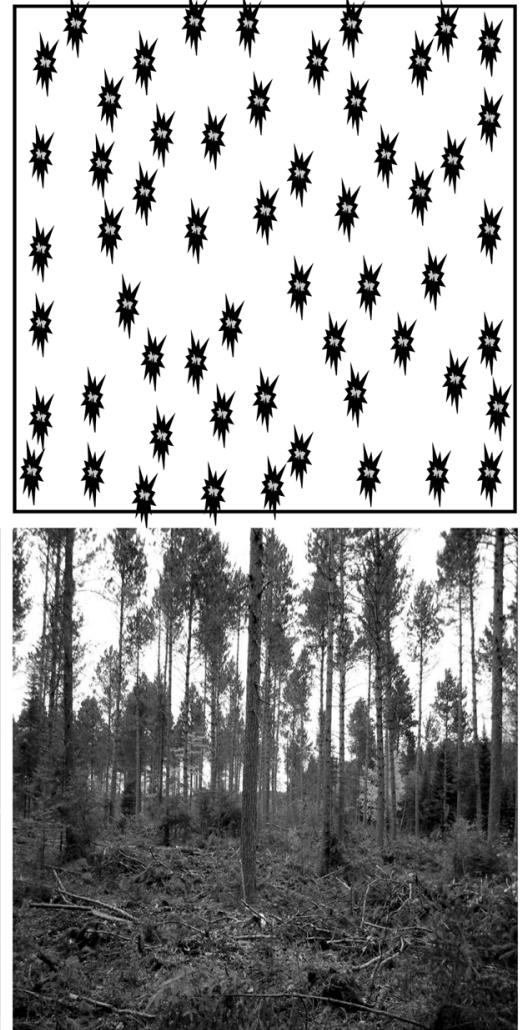
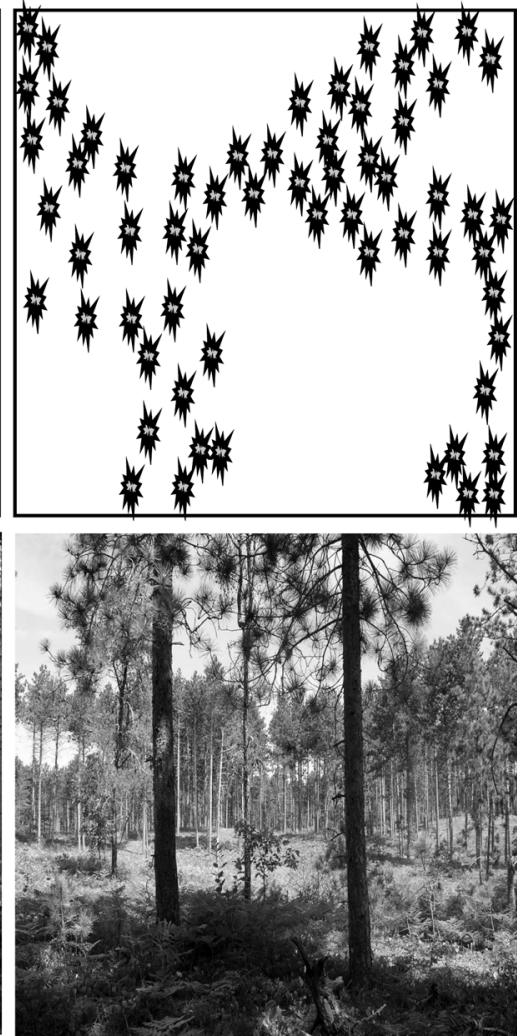

FIG. 1. (Top) Conceptual representation of spatial pattern of retention after variable-retention harvesting (VRH) in (a) uncut control, (b) dispersed, and (c) aggregated treatments, and (bottom) examples of each treatment shortly after harvesting.

regeneration of other, mostly hardwood, species (not addressed in this study). As such, the planted cohort of pines likely did not fully occupy the regeneration niche of these forests and might best be viewed as a phytometer of resource competition in our treatments. The entire stand was planted for each replicate of the two harvest treatments. Planting in the control stands (no overstory cutting) was restricted to smaller plots associated with measurements. Each fall, the planted seedlings were sprayed with Plantskydd (Tree World, Des Moines, Iowa, USA), a chemical repellent that discourages browsing by Odocoileus virginianus (whitetailed deer) and Lepus americanus (snowshoe hare). Browsing control was applied annually from 2002 through 2007.

\section{Sampling design}

In each stand, we established a network of sample points to serve as loci for measurements. There were 20-24 points in each stand, equally divided between shrub treatments. Points spanned the range of overstory conditions, but were excluded from the first $30 \mathrm{~m}$ of stand boundaries to avoid edges. We measured diameters of trees (stems $\geq 2.5 \mathrm{~cm}$ diameter at $1.4 \mathrm{~m}$; dbh hereafter) in $11.4 \mathrm{~m}$ radius plots centered on each sampling point. In the early spring 2003 after harvest, trees in each plot were identified to species, tagged, mapped for location, and measured for diameter to the nearest $0.1 \mathrm{~cm}$. For this study, trees were re-measured in winter 2008 (six years of growth). Diameter measurements were used in allometric equations to estimate aboveground biomass (see Allometric biomass estimation). The shrub layer (woody stems $>0.5 \mathrm{~m}$ tall to $2.5 \mathrm{~cm} \mathrm{dbh}$ ) was sampled three times between 2004 and 2008 in a $1.26 \mathrm{~m}$ radius circular plot centered on each sampling point. Stems were counted and identified to species.

In spring 2003 after planting, five seedlings of each pine species were selected randomly in each tree sampling plot for repeated diameter measurements. Seedlings were selected without bias regarding health (at this early point in the study all seedlings appeared equally healthy). Seedlings were tagged and measured for diameter at the root collar in spring 2003 and fall of 2009 (seven growing seasons). Diameter measurements were used in allometric equations to estimate aboveground biomass (see Allometric biomass estimation).

\section{Allometric biomass estimation}

We used published allometric equations for the species in our study (Perala and Alban 1993, Jenkins et al. 2004) to estimate aboveground biomass of overstory trees. Biomass was calculated in 2003 after 
harvest and again in 2008 (six growing seasons), with the difference reflecting aboveground biomass growth over the study period. Biomass growth components included residual trees (those alive in 2003 and 2008), ingrowth into the tree size class $(\geq 2.5 \mathrm{~cm} \mathrm{dbh})$ over the six-year period, and mortality (trees that were alive in 2003 but dead by 2008). Plot level data from each treatment was averaged and scaled up to a per-ha basis. We recognize that use of regional equations for biomass estimation can introduce error, particularly when estimates for multiple species (each with its own associated error) are summed together, as in this study. However, the majority $(>90 \%)$ of biomass in our study was composed of Pinus resinosa trees and the equation we used for this species came from study sites in the western Great Lakes states, as did the equations used for all of the other important sub-dominant species. Moreover, it is likely that any error accumulation was similar among the three treatments, as the proportion of different species in each was similar. Thus, a comparison of biomass growth among treatments should be valid, even if the absolute numbers have error associated with them.

We used data from several sources to construct allometric aboveground biomass equations (using basal diameter) for the planted pine seedlings. At the time of planting we recorded root-collar diameters and determined aboveground biomass for a sample of the planting stock to estimate initial biomass. We destructively harvested seedlings (other than those we followed) over the next several years to extend our data ranges. Additionally, we used data for the same species collected as part of a companion study (Montgomery et al. 2010) to extend the size ranges to those encountered by 2009 . Mean aboveground biomass per ha in 2003 was estimated using average seedling biomass multiplied by initial planting density. We used initial planting densities and seventh-year survival of our planted pine seedlings to estimate stand-wide densities by treatment in 2009 . Aboveground biomass in 2009 was estimated by species for each plot based on average seedling biomass for that plot multiplied by 2009 density. The difference between 2009 and 2003 reflected biomass growth during the study period. Plot level data from each treatment was averaged and scaled up to a per-hectare basis.

\section{Data analysis}

We analyzed for mean differences among treatments in biomass growth of retained trees and the new cohort, as well as other vegetation components (basal area, shrub density, seedling density) using a mixed-model randomized block, split-plot ANOVA, where block was the random factor, overstory treatment was the fixed main plot factor, and shrub treatment was the fixed split-plot factor (note that interaction between overstory treatment and shrub treatment was not significant in any of these tests; $P=0.20$ or greater). If the overall test was significant, we used orthogonal contrasts to compare (1) the control with pooled retention treatments and (2) dispersed retention with aggregated retention. Data were transformed with square root or log transformations when necessary to meet statistical assumptions and means of these data were back-transformed for reporting (with $95 \%$ confidence intervals as an estimate of variability).

For comparison to the retention treatments, we summarized planted seedling growth using plots that occurred in the center of the 0.3-ha openings that were part of the aggregated treatment (whereas the aggregated treatment included all plots from the full range of canopy conditions in a stand). We called this the "open" treatment, as it putatively represented conditions in small clearcuts. We did not, however, include the open treatment in statistical analysis, as these plots were not independent of the aggregated treatment in which they occurred.

\section{Results}

\section{Forest structure}

Pre-harvest basal area of trees $(\mathrm{dbh} \geq 2.5 \mathrm{~cm})$ was similar among all 24 treatment units (three overstory treatments $\times$ two understory treatments $\times$ four replicates), averaging $37.3 \mathrm{~m}^{2} /$ ha $\left(95 \% \mathrm{CI}, 34.7-39.8 \mathrm{~m}^{2} / \mathrm{ha}\right)$. Pre-harvest basal area did not differ among overstory treatments $(P=0.52)$ or between shrub treatments $(P=$ $0.49)$. After harvest, basal area of the pooled retention treatments was significantly lower than the control $(P<$ $0.0001)$, but did not differ from each other $(P=0.31)$ or between shrub treatments $(P=0.47)$, averaging $\sim 17 \mathrm{~m}^{2} /$ ha (Fig. 2). The percentage reduction in basal area among the 16 harvested units (two overstory treatments $\times$ two understory treatments $\times$ four replicates) was similar, averaging 57\% (95\% CI, 52\%-61\%).

Patterns among treatments in aboveground biomass of trees immediately after harvest in 2003 were similar to patterns for basal area (Fig. 2). The difference in biomass between the retention treatments $(\sim 63 \mathrm{Mg}$ / ha) and control $(\sim 158 \mathrm{Mg} / \mathrm{ha})$ was significant $(P<$ $0.0001)$, but the two retention treatments did not differ significantly from each other $(P=0.67)$, nor was there a difference between shrub treatments $(P=0.42)$.

Densities of planted seedlings in 2003 (all species pooled) averaged 1211 seedlings/ha (95\% CI, 1142-1279 seedlings/ha) among the 24 treatment units and differed marginally among overstory treatments $(P=0.07)$, averaging $\sim 1132$ seedlings/ha (95\% CI, 1064-1200/ha) in the two retention treatments and 1368 seedlings/ha (95\% CI, 1290-1447/ha) in the control, but did not differ between shrub treatments $(P=0.34)$. There were no significant differences $(P=0.14-0.87)$ in initial densities among either overstory or shrub treatments when species were examined separately.

Initial aboveground biomass of planted pine seedlings (all three species pooled) in 2003 averaged $4.7 \mathrm{~kg} / \mathrm{ha}$ (95\% CI, 4.4-5.0 kg/ha) among the 24 treatment units and differed marginally among overstory treatments $(P$ $=0.07)$, averaging $4.4 \mathrm{~kg} / \mathrm{ha}(95 \% \mathrm{CI}, 4.2-4.7 \mathrm{~kg} / \mathrm{ha})$ in 

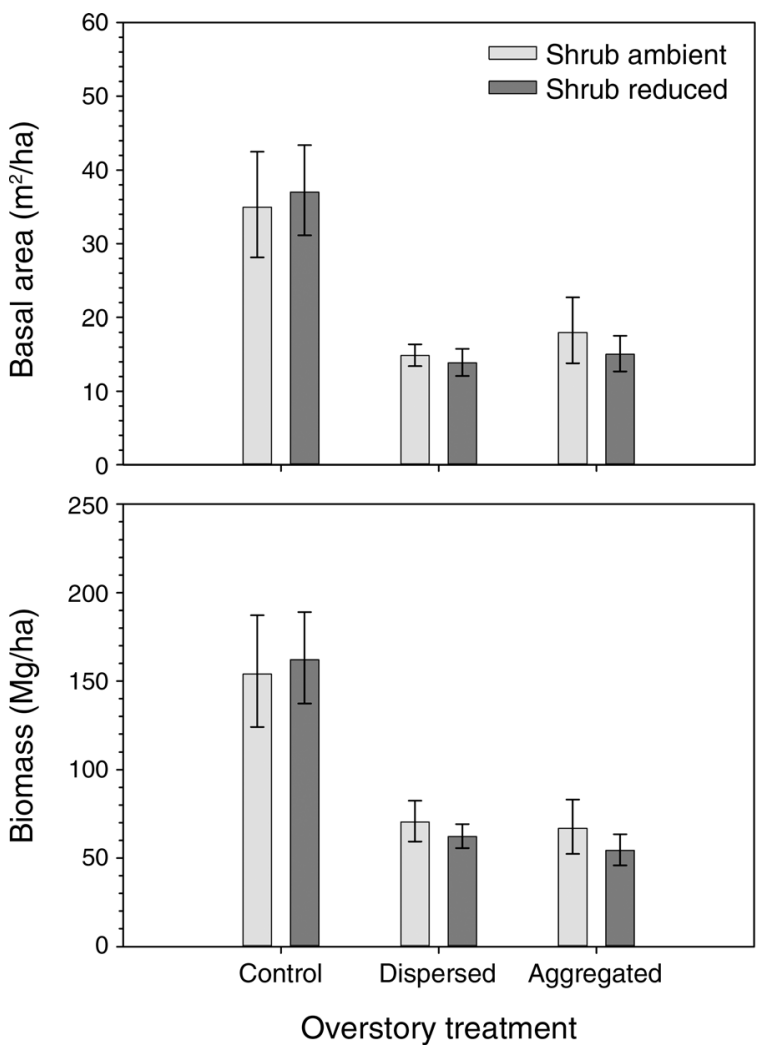

FIG. 2. (Top) Basal area $\left(\mathrm{m}^{2} / \mathrm{ha}\right)$ and (bottom) aboveground biomass $(\mathrm{Mg} / \mathrm{ha}$ ) of trees with $\mathrm{dbh} \geq 2.5 \mathrm{~cm}$ (at $1.4 \mathrm{~m}$ from the ground) in 2003 (immediately after harvest) in control forest and VRH treatments, with and without woody shrub reduction, in red pine forests in northern Minnesota, USA. Values are means ( $n=4$ replicate blocks) with $95 \%$ confidence intervals.

the two retention treatments and $5.2 \mathrm{~kg} / \mathrm{ha}(95 \% \mathrm{CI}$, 4.9-5.6 kg/ha) in the control, but not between shrub treatments $(P=0.96)$. Again, there were no differences among overstory treatments or between shrub treatments when initial aboveground biomass was examined separately by species $(P=0.14-0.87)$.

Mean shrub densities before treatment in 2002 averaged 12999 stems/ha (95\% CI, 9889-16 109 stems/ha) among the 24 treatment units and did not differ among overstory treatments $(P=0.50)$ or shrub treatments $(P=0.82)$. Over time, density of the shrub reduction treatment $(\sim 3275$ stems/ha in 2008) was maintained at a value significantly lower than the ambient shrub treatment $(\sim 14470$ stems/ ha in 2008; $P>0.0001$ ), although values in the latter were quite variable within overstory treatments, particularly in the openings of the aggregated treatment (Fig. 3). Shrub densities did not differ among the retention treatments themselves within each shrub treatment $(P=0.19)$ (Fig. 3).

\section{Planted seedling biomass response}

Annual aboveground biomass growth in the cohort of planted pines ranged 64 -fold, from $0.4 \mathrm{~kg} \cdot \mathrm{ha}^{-1} \cdot \mathrm{yr}^{-1}$ in the overstory control/ambient shrub treatment to 22.7

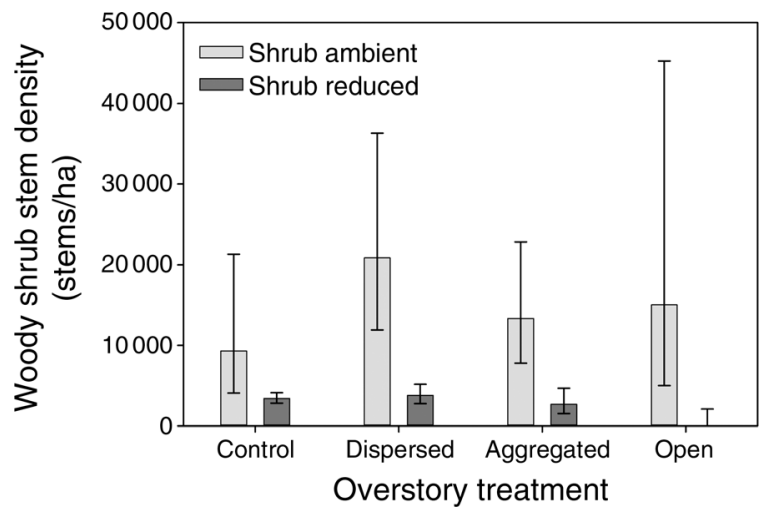

FIG. 3. Average density (stems/ha) of woody shrubs (stems $>0.5 \mathrm{~m}$ tall and $<2.5 \mathrm{~cm} \mathrm{dbh}$ ) in 2008 in control forest and VRH treatments, with and without shrub reduction, in red pine forests in northern Minnesota, USA. Values are means $(n=4$ replicate blocks) with $95 \%$ confidence intervals.

$\mathrm{kg} \cdot \mathrm{ha}^{-1} \cdot \mathrm{yr}^{-1}$ in the aggregated retention/shrub reduction treatment (Fig. 4). For comparison, seedling biomass growth in the large openings (only) was even higher (17.4 $\mathrm{kg} \cdot \mathrm{ha}^{-1} \cdot \mathrm{yr}^{-1}$, ambient shrub; $45.7 \mathrm{~kg} \cdot \mathrm{ha}^{-1} \cdot \mathrm{yr}^{-1}$, shrub reduction). Seedling biomass growth was significantly lower in the overstory control compared to the retention treatments $(P<0.0001)$, but did not differ between the dispersed and aggregated treatments $(P=$ 0.97). The differences in biomass growth among overstory treatments were largely due to differences in seedling size, as densities by 2009 , and therefore mortality rates, did not differ by overstory treatment $(P=0.14)$, averaging 849 stems/ha $(95 \% \mathrm{CI}, 765-933$ stems/ha) among all treatments. Biomass growth was significantly higher in the shrub reduction treatment compared to the ambient shrub treatment $(P=0.001)$, particularly in the two retention treatments (Fig. 4). This was due mostly to increased seedling size, but also somewhat higher seedling densities (3-11\% higher in the

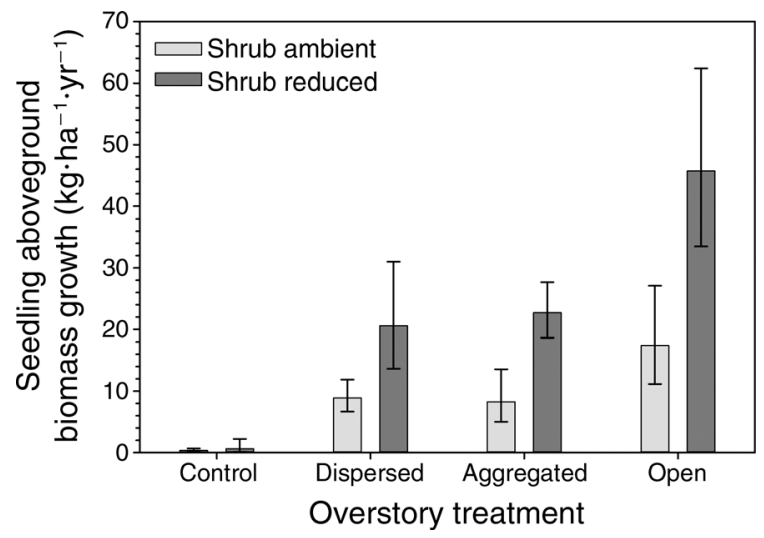

FIG. 4. Average annual aboveground biomass growth $\left(\mathrm{kg} \cdot \mathrm{ha}^{-1} \cdot \mathrm{yr}^{-1}\right)$ of planted pine seedlings in control forests and VRH treatments, with and without woody shrub reduction, in red pine forests in northern Minnesota, USA. Values are means ( $n=4$ replicate blocks) with $95 \%$ confidence intervals. 


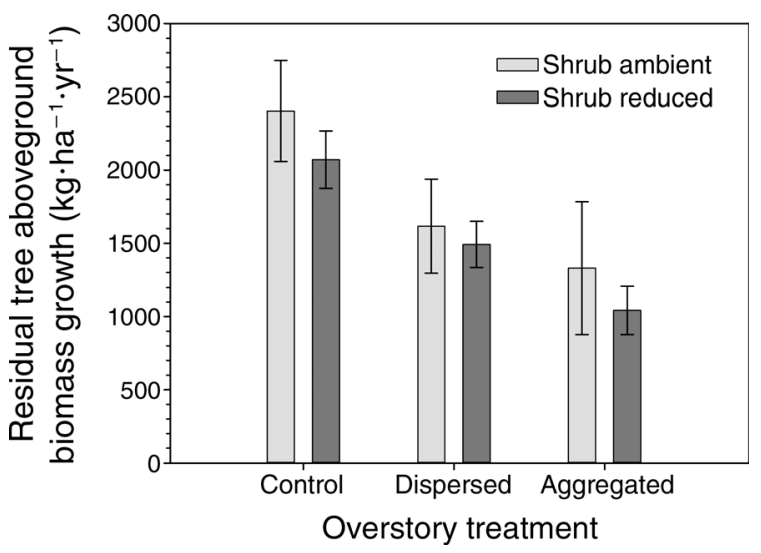

FIG. 5. Average annual aboveground biomass growth $\left(\mathrm{Mg} \cdot \mathrm{ha}^{-1} \cdot \mathrm{yr}^{-1}\right)$ of retained overstory trees $(\mathrm{dbh} \geq 2.5 \mathrm{~cm})$ in control forest and VRH treatments, with and without woody shrub reduction, in red pine forests in northern Minnesota, USA. Values are means ( $n=4$ replicate blocks) with $95 \%$ confidence intervals.

shrub reduction treatment compared to ambient shrub treatment; $P=0.005$ ).

A similar pattern of biomass growth was evident when planted seedlings were examined individually by species (data not shown). That is, biomass growth for each species was significantly higher in the retention treatments than the control $(P<0.0001)$, but did not differ between retention treatments $(P=0.20-0.35)$, and was higher in the shrub reduction treatment than the ambient shrub treatment $(P=0.0007-0.02)$. The biomass growth responses of surviving Pinus banksiana and Pinus strobus were largely due to growth, as densities in 2009 did not differ among overstory treatments or shrub treatments for either species $(P=$ 0.09-0.32). Densities of surviving Pinus resinosa differed somewhat among overstory treatments and shrub treatments in 2009. There was very low surviving Pinus resinosa density in the overstory control treatment for both shrub treatments (50 stems/ha, 95\% CI, $-0.2-101$ stems/ha), with zero values recorded in two blocks (this treatment was not included in the statistical analysis). Densities in the four retention-harvesting-shrub-treatment combinations were much higher than the control: dispersed harvesting, ambient shrub $=242$ stems $/$ ha (145-338 stems/ha); dispersed harvesting, reduced shrub $=363 \mathrm{stems} / \mathrm{ha}(207-518 \mathrm{stems} / \mathrm{ha})$; aggregated harvesting, ambient shrub $=264$ stems/ha (173-356 stems/ha); aggregated harvesting, reduced shrub $=276$ stems $/$ ha (204-348 stems/ha). Densities in the dispersed-harvesting, reduced-shrub treatment were significantly higher than the dispersed-harvesting, ambient-shrub treatment $(P=0.03)$; no other comparisons were significantly different.

\section{Residual tree biomass responses}

Annual stand-level aboveground biomass growth of live residual trees $(\mathrm{dbh} \geq 2.5 \mathrm{~cm})$ ranged from a high of
$2404 \mathrm{~kg} \cdot \mathrm{ha}^{-1} \cdot \mathrm{yr}^{-1}$ in the uncut-control, ambient-shrub treatment to a low of $1043 \mathrm{~kg} \cdot \mathrm{ha}^{-1} \cdot \mathrm{yr}^{-1}$ in the aggregated-retention, shrub-reduction treatment (Fig. 5). Surviving trees accounted for over $98 \%$ of total biomass growth, as in-growth and mortality were relatively small (data not shown). The difference in biomass growth was significant between the control and pooled retention treatments $(P=0.003)$, and marginally so between dispersed and aggregated retention $(P=$ 0.09 ). Surprisingly, annual biomass growth was $\sim 10 \%$ higher in the ambient shrub vs. shrub reduction treatment $(P=0.025$; Fig. 5$)$.

Annual aboveground biomass growth of just the large trees $(\mathrm{dbh}>20 \mathrm{~cm})$ paralleled the response pattern of all trees and accounted for $98 \%$ of total growth (data not shown). The difference in biomass growth of large trees was significant between the control and pooled retention treatments $(P=0.003)$, but did not differ between dispersed and aggregated retention $(P=0.16)$. Biomass growth of large trees was $\sim 14 \%$ higher in the ambient shrub vs. the shrub reduction treatment $(P=0.09)$.

\section{DisCusSION}

For VRH systems, it is hypothesized that the spatial pattern of retention can be altered to achieve different outcomes for a variety of ecosystem characteristics and processes (Franklin et al. 1997, Aubry et al. 2009), including resource availability in the understory, competitive environments for tree regeneration (Palik et al. 2003), and growth of residual trees (Maguire et al. 2006). In this study, we used an operational-scale VRH experiment in Pinus resinosa forests to assess aspects of this hypothesis, specifically by examining how spatial pattern of retention influences biomass growth of residual trees, as well as a new cohort of planted seedlings and competing woody shrubs.

\section{New cohort biomass responses to retention pattern}

In prior work, we demonstrated that our retention treatments influenced the availability of light and to a lesser degree nitrogen in the forest understory of our experiment, with highest stand-level values in the aggregated treatment when shrubs were reduced (Boyden et al. 2012, Montgomery et al. 2013). Different retention patterns (dispersed, aggregated) modify heterogeneity in resource supply at the whole-stand scale by changing the spatial distribution of tree basal area and thus the frequency of different resource neighborhoods within stands (Palik et al. 2003, Boyden et al. 2012). Dispersed retention results in uniformly lower tree basal areas across the stand and few neighborhoods experience a low enough level of competition to experience high resource availability. With aggregated retention, areas within residual patches will be highly competitive, but openings between patches will have low levels of competition from the overstory and with reductions in competing shrubs, regenerating seedlings experience higher resource availability. Differences in resource 
availability with retention pattern should translate into parallel responses in growth of new regeneration, as has been shown in other systems (Palik et al. 2003).

Our first hypothesis was predicated on these patterns in resource availability and target plant growth: Standlevel aboveground biomass growth of a new cohort of planted seedlings will be highest with aggregated rather than dispersed retention, even when holding residual overstory basal area constant. Our results, however, do not support this hypothesis. Biomass growth of the new cohort of planted seedlings did not differ between aggregated and dispersed retention, suggesting that the resource differences we documented in prior work did not lead to differences in average acquisition rates and growth responses at the stand-scale, at least as we measured them in this study. For comparison, the large open areas of the aggregated retention treatments presumably had greatly reduced competition from overstory trees, since biomass growth of regeneration within these openings (within each shrub treatment) was substantially higher than stand averages in either the dispersed or aggregated retention treatments. We suspect that the level of residual basal area was high enough, stand-wide, that even with aggregated retention, there were too few of these open neighborhoods where regeneration was effectively "released" from competition (that is, not enough to result in stand-wide differences compared to dispersed retention). Alternatively, simultaneous facilitation and competition effects (Montgomery et al. 2010) might occur in both open and crowded neighborhoods, with both facilitation and competition having greater effects in more crowded neighborhoods, but with the balance of the two being similar. However, we were unable to test either of these hypotheses in our study because (1) level of residual basal area was not manipulated independently of spatial pattern and (2) measurements to separate competition from facilitation were beyond the scope of this study.

Several studies document reduced growth of regeneration with dispersed (vs. aggregated) retention, particularly for species that are intermediate to intolerant of shade (Urgenson et al. 2013), or at high levels of retention (Mitchell et al. 2007). However, comparisons are typically made between dispersed retention and the clearcut areas of aggregated retention, rather than between stand-wide averages that integrate the full range of environmental heterogeneity that seedlings encounter, as we did in this study. In the only other experiment we are aware of that examined the full range of canopy conditions in VRH stands, diameter growth of Pinus palustris (longleaf pine), a species classified as intolerant of shade (Burns and Honkala 1990), was significantly greater with aggregated than with dispersed retention (Palik et al. 2003).

Our planted seedling species ranged from intermediate to very intolerant of shade. We suspected that growth responses to spatial pattern of retention might differ among these species, such that the lack of response we observed when the species were pooled in our analysis reflected this mixture of tolerances. However, biomass growth responses to treatment were very similar when examined separately by species, suggesting that differences in tolerance were not extreme enough to illicit differences in growth responses to retention pattern.

In our experiment, the biomass responses to retention pattern were largely due to growth differences, as initial and final seedling densities did not differ among overstory treatments. Similar observations have been made in other studies, where survival of planted seedlings after several years was largely invariant to retention pattern (Palik et al. 2003, Urgenson et al. 2013).

\section{Woody shrub competition}

Research has shown that resource preemption by preestablished understory vegetation is an important factor controlling regeneration in forest ecosystems (e.g., Perry et al. 1993, Lorimer et al. 1994, Bush and Van Auken 1995) and, specifically, that a woody shrub layer inhibits Pinus strobus establishment and growth in ecosystems similar to the one we studied (Dovciak et al. 2003, Weyenberg et al. 2004). Moreover, in related work, we demonstrated that reduction of pre-established shrubs, largely Corylus cornuta and $C$. americana, increases resource availability to the understory (Montgomery et al. 2010). By preempting resources, woody shrubs develop an initial competitive advantage over neighboring plants that increases over time. Conversely, reduction of shrubs should increase resource availability and decrease competitive inhibition of tree regeneration. This was the rationale for our second hypothesis: Biomass growth of the new cohort of planted seedlings will increase with woody shrub reduction, partially compensating for growth reductions that occur with overstory retention. Our results support the existence of strong competitive inhibition of tree regeneration by woody shrubs, as biomass growth of planted seedlings was significantly reduced $(60 \%$ lower) in the presence of shrubs in the retention treatments and in the openings. Thus, our hypothesis was supported, in that growth reductions due to competition from the residual overstory in the VRH treatments was lessened with shrub reduction. In fact, average biomass growth of seedlings in retention treatments with shrub reduction exceeded that in the openings that had ambient shrub densities.

\section{Residual tree biomass response}

The focus on growth responses in VRH experiments has generally been on regeneration cohorts, with considerably less research on the growth of retention trees and none that we are aware of that examines residual tree biomass responses to retention pattern. We believe the reason for this is that VRH systems are generally thought of as alternatives to even-aged regeneration systems, so the focus is understandably 
on the response of a regeneration cohort. However, a more appropriate and comprehensive view of VRH systems is one that recognizes that one goal of such systems is to create complex early successional habitats that emulate the structural outcomes of natural disturbance. Under this view, the growth response of residual trees becomes equally important as that of a new cohort of trees.

We addressed the growth response of the residual cohort of trees with our third hypothesis: Aboveground biomass growth of the residual overstory will be greatest with dispersed retention compared to aggregated retention. This hypothesis is predicated on the assumption that resource competition will be high within dense tree patches in aggregated retention, such that growth differentiation will develop among retention trees, even in relatively small patches with high edge influences. In contrast, the majority of trees in dispersed retention stands should experience less competition for light (than in aggregated retention), and perhaps soil resources as long as shrubs do not preemptively take up this "surplus." Prior research on radial growth increases of individual trees is suggestive of this response pattern (Powers et al. 2010), in that radial growth was highest with dispersed retention and lowest with aggregated retention.

Our results from the current study, on stand-level biomass growth, lend support to our hypothesis. Standlevel residual tree biomass growth was marginally (10\%) higher with dispersed retention than with aggregated retention. The pattern of residual tree biomass growth in large trees $(\geq 20 \mathrm{~cm} \mathrm{dbh})$ paralleled that seen in all trees, but the difference between aggregated and dispersed retention was not significant in this case, suggesting that the response of trees smaller than $20 \mathrm{~cm}$ dbh to spatial pattern was important. In particular, smaller trees likely had greater resource availability under dispersed retention and were able to contribute significantly to standlevel biomass growth responses.

Unexpectedly, biomass growth of trees was higher in the ambient shrub treatment compared to the shrub reduction treatment. Further exploration of this pattern is needed. Mechanical shrub removal should not have damaged residual trees, particularly the larger ones. Shrub reduction, by also reducing annual leaf litter inputs, may have lowered input of nutrients in litter fall, (but also would reduce competition for nutrients and moisture); however, soil $\mathrm{N}$ and $\mathrm{P}$ availability was generally higher, although not significantly so, in the shrub reduction treatment (Montgomery et al. 2013).

\section{Management application}

VRH systems have become a popular tool worldwide to more closely emulate some of the outcomes of natural canopy disturbance. The goal may be to create structurally complex early successional conditions in managed forests (Swanson et al. 2011) or to better balance production and ecological objectives, e.g., biodiversity conservation, in a managed setting (Gustafsson et al. 2012, Lindenmayer et al. 2012). In our case, there is substantial evidence that Pinus resinosa ecosystems occurred naturally in two or even three cohort age structures that were similar in spatial pattern to those we created in our experiment (Fraver and Palik 2012), providing some ecological justification for VRH approaches in this ecosystem.

One concern regarding retention systems, with $P$. resinosa and other ecosystems, is that the ecological benefits of tree retention may come at the cost of lowered growth of a new cohort of trees. This is likely true, particularly for less-tolerant tree species, as demonstrated by many decades of research on regeneration response to overstory competition in a variety of forest ecosystems (e.g., Birch and Johnson 1992, Acker et al. 1998, Dignan et al. 1998, Huffman et al. 1999).

We hypothesized that VRH systems can be designed to lessen growth losses of the new cohort of trees by manipulating the spatial distribution of resource neighborhoods in VRH stands by aggregating retention, and that growth of the regeneration cohort could be increased by reducing shrub competition. In our study, we found that aboveground biomass growth of a planted seedling cohort was actually similar with aggregated and dispersed retention. However, growth of this cohort did increase with woody shrub reduction, and in fact, shrub reduction influenced growth to a much greater degree than did retention pattern. These results suggest that forest managers can exercise great flexibility in application of VRH and still have similar expectations for biomass growth of regeneration. That is, they can meet different ecosystem goals across the landscape by varying retention pattern and still have similar regeneration growth responses. Moreover, our results provide strong support for the importance of competition control (of woody shrubs) for regeneration success in VRH systems; with inclusion of a shrub reduction treatment, managers can negate much of the growth reductions of regeneration that result from overstory retention. In fact, doing so better emulates the outcomes of frequent low-intensity surface fires that maintained low densities of woody shrubs in these ecosystems (Heinselman 1973, Sands and Abrams 2011).

Our third hypothesis was that biomass growth of the residual trees would be highest with dispersed retention compared to aggregated retention, which proved to be marginally the case. This suggests that managers should consider the growth of the residual cohort of trees, and how it might be altered with spatial pattern of retention, as part of a holistic perspective on VRH systems. The complex stand structure provided by residual trees, particularly when the spatial pattern of retention varies across the landscape, has important ecological benefits related to wildlife habitat, seed sources, and microclimate (Franklin et al. 1997). It is particularly important to factor growth of the residual cohort into assessment of VRH in systems when mortality of these trees is low, 
when the species retained are long-lived, and when individual trees show positive growth responses to density reduction at mature and old ages, all of which are true for the Pinus resinosa forest we studied (D'Amato et al. 2010). The management implication is that retained trees in systems like ours will contribute to stand growth for a considerable time in these forests. In summary, similar expectations for new cohort and retained cohort biomass growth in response to spatial pattern of retention, as well as the mediating influence of an understory woody shrub layer on responses, should be valid for other forest ecosystems with similar structure and dynamics.

\section{ACKNOWLEDGMENTS}

We thank Christel Kern, Kathryn Lang, Doug Kastendick, and Susan Barrott for field crew supervision and data organization, and Kelly Barrett, Barb Knight, and the Deer River Ranger District of the Chippewa National Forest for logistical support in implementing the silvicultural research design. Thanks to the numerous students and members of short-term field crews for field data collection. Funding was provided by USDA NRI CREES Award No. 2006-3510117061, the US Forest Service Northern Research Station and the Chippewa National Forest, the Wilderness Research Foundation, and the Minnesota Agricultural Experiment Station MIN-42-074. Tony D'Amato and several anonymous reviewers provided comments that improved on an earlier draft of the manuscript.

\section{Literature Cited}

Acker, S. A., E. K. Zenner, and W. H. Emmingham. 1998. Structure and yield of two-aged stands on the Willamette National Forest, Oregon: implications for green tree retention. Canadian Journal of Forest Research 28:749-758.

Atwell, R. C., L. A. Schulte, and B. J. Palik. 2008. Songbird response to experimental retention harvesting in red pine (Pinus resinosa) forests. Forest Ecology and Management 255:3621-3631

Aubry, K. B., C. B. Halpern, and D. A. Maguire. 2004. Ecological effects of variable retention harvests in the northwestern United States: the DEMO study. Forest, Snow, and Landscape Research 78:119-137.

Aubry, K. B., C. B. Halpern, and C. E. Peterson. 2009. Variable-retention harvests in the Pacific Northwest: a review of short-term findings from the DEMO study. Forest Ecology and Management 258:398-408.

Baker, S. C., T. A. Spies, T. J. Wardlaw, J. Balmer, J. F. Franklin, and G. J. Jordan. 2013. The harvested side of edges: Effect of retained forests on the re-establishment of biodiversity in adjacent harvested areas. Forest Ecology and Management 302:107-121.

Bebber, D. P., S. C. Thomas, W. G. Cole, and D. Balsillie. 2004. Diameter increment in mature eastern white pine Pinus strobus L. following partial harvest of old-growth stands in Ontario, Canada. Trees 18:29-34.

Beese, W. J., B. G. Dunsworth, K. Zielke, and B. Bancroft. 2003. Maintaining attributes of old-growth forests in coastal B.C. through variable retention. Forestry Chronicle 79:570578.

Birch, K., and K. N. Johnson. 1992. Stand-level woodproduction costs of leaving live, mature trees at regeneration harvest in coastal Douglas-fir stands. Western Journal of Applied Forestry 3:65-68.

Blake, T. J., and C. W. Yeatman. 1989. Water relations, gas exchange, and early growth rates of outcrossed and selfed Pinus banksiana families. Canadian Journal of Botany 67:1618-1623.
Boyden, S., R. Montgomery, P. B. Reich, and B. Palik. 2012. Seeing the forest for the heterogeneous trees: stand-scale resource distributions emerge from tree-scale structure. Ecological Applications 22:1578-1588.

Buckley, D. S., T. L. Sharik, and J. G. Isebrands. 1998. Regeneration of northern red oak: positive and negative effects of competitor removal. Ecology 79:65-78.

Burns, R. M., and B. H. Honkala. 1990. Silvics of North America: 1. Conifers. Agriculture Handbook 654. Volume 2. USDA Forest Service, Washington, D.C., USA.

Bush, J. K., and O. W. Van Auken. 1995. Woody plant growth related to planting times and clipping of $\mathrm{C}_{4}$ grass. Ecology 76:1603-1609.

Coates, K. D. 2000. Conifer seedling response to northern temperate forest gaps. Forest Ecology and Management 127:249-269.

D'Amato, A. W., B. J. Palik, and C. C. Kern. 2010. Growth, yield, and structure of extended rotation red pine stands in Minnesota. Canadian Journal of Forest Resources 40:1000 1010.

Dignan, P., M. King, A. Saveneh, and M. Walters. 1998. The regeneration of Eucalyptus regans F. Muell. under retained overwood: seedling growth and density. Forest Ecology and Management 102:1-7.

Dovciak, M., L. E. Frelich, and P. B. Reich. 2003. Seed rain, safe sites, competing vegetation and soil resources spatially structure white pine regeneration and recruitment. Canadian Journal of Forest Research 33:1892-1904.

Drever, C. R., G. Peterson, C. Messier, Y. Bergeron, and M. Flannigan. 2006. Can forest management based on natural disturbances maintain ecological resilience? Canadian Journal of Forest Research 36:2285-2299.

Drobyshev, I., P. C. Goebel, D. M. Hix, R. G. Corace III, and M. E. Semko-Duncan. 2008. Interactions among forest composition, structure, fuel loadings and fire history: a case study of red pine-dominated forests of Seney National Wildlife Refuge, Upper Michigan. Forest Ecology and Management 256:1723-1733.

Franklin, J. F., D. R. Berg, D. A. Thornburgh, and J. C. Tappeiner. 1997. Alternative silvicultural approaches to timber harvesting: variable retention harvest systems. Pages 111-139 in K. A. Kohm and J. F. Franklin, editors. Creating a forestry for the 21 st century: the science of ecosystem management. Island Press, Washington, D.C., USA.

Franklin, J. F., D. B. Lindenmayer, J. A. MacMahon, A. McKee, J. Magnusson, D. A. Perry, R. Waide, and D. R. Foster. 2000. Threads of continuity: ecosystem disturbances, biological legacies, and ecosystem recovery. Conservation Biology in Practice 1:8-16.

Franklin, J. F., R. J. Mitchell, and B. J. Palik. 2007. Natural disturbance and stand development principles for ecological forestry. USDA Forest Service General Technical Report NRS-19. USDA Forest Service, Northern Research Station, Newtown Square, Pennsylvania, USA.

Franklin, J. F., et al. 2002. Disturbances and structural development of natural forest ecosystems with silvicultural implications, using Douglas-fir forests as an example. Forest Ecology and Management 155:399-423.

Fraver, S., and B. J. Palik. 2012. Stand and cohort structures of old-growth Pinus resinosa-dominated forests of northern Minnesota, USA. Journal of Vegetation Science 23:249-259.

Frissell, S. S. 1973. The importance of fire as a natural ecological factor in Itasca State Park, Minnesota. Quaternary Research 3:397-407.

Gradowski, T., V. J. Lieffers, S. M. Landhäusser, D. Sidders, J. Volney, and J. R. Spence. 2010. Regeneration of Populus nine years after variable retention harvest in boreal mixedwood forests. Forest Ecology and Management 259:383-389.

Gustafsson, L., et al. 2012. Retention forestry to maintain multifunctional forests: a world perspective. BioScience 62:633-645. 
Heinselman, M. L. 1973. Fire in the virgin forests of the Boundary Waters Canoe Area, Minnesota. Quaternary Research 3:329-382.

Heinselman, M. L. 1999. The Boundary Waters wilderness ecosystem. University of Minnesota Press, Minneapolis, Minnesota, USA.

Huffman, R. D., M. A. Fajvan, and P. B. Wood. 1999. Effects of residual overstory on aspen development in Minnesota. Canadian Journal of Forest Research 29:284-289.

Jenkins, J. C., D. C. Chojnacky, L. S. Heath, and R. A. Birdsey. 2004. Comprehensive database of diameter-based biomass regressions for North American tree species. USDA Forest Service General Technical Report NE-319. USDA Forest Service, Northern Research Station, Newtown Square, Pennsylvania, USA.

Lindenmayer, D. B., and J. F. Franklin. 2002. Conserving forest biodiversity: a comprehensive multiscaled approach. Island Press, Washington, D.C., USA.

Lindenmayer, D. B., et al. 2012. A major shift to the retention approach for forestry can help resolve some global forest sustainability issues. Conservation Letters 5:421-431.

Lorimer, C. G., J. W. Chapman, and W. D. Lambert. 1994. Tall understory vegetation as a factor in the poor development of oak seedlings beneath mature stands. Journal of Ecology $82: 227-237$

Maguire, D. A., D. B. Mainwaring, and C. B. Halpern. 2006. Stand dynamics after variable retention harvesting in mature Douglas-fir forests of Western North America. Allgemeine Forst und Jagdseitung 177:120-131.

Mitchell, A. K., R. Koppenall, G. Goodmanson, R. Benton, and T. Bown. 2007. Regenerating montane conifers with variable retention systems in a coastal British Columbia forest: 10-year results. Forest Ecology and Management 246:240-250.

Montgomery, R. A., B. J. Palik, S. B. Boyden, and P. B. Reich. 2013. New cohort growth and survival in variable retention harvests of a pine ecosystem in Minnesota, USA. Forest Ecology and Management 310:327-335.

Montgomery, R., P. Reich, and B. Palik. 2010. Untangling positive and negative biotic interactions: views from above and below ground in a forest ecosystem. Ecology 91:36413655.

Newsome, T. A., J. L. Heineman, A. F. Linnell Nemec, P. G. Comeau, A. Arsenault, and M. Waterhouse. 2010. Ten-year regeneration responses to varying levels of overstory retention in two productive southern British Columbia ecosystems. Forest Ecology and Management 260:132-145.

Ostry, M. E., M. Moore, C. C. Kern, R. C. Venette, and B. J. Palik. 2012. Multiple diseases impact survival of planted red, jack, and white pine seedlings in red pine stands harvested in spatially variable retention patterns. Forest Ecology and Management 286:66-72.

Palik, B. J., R. Mitchell, G. Houseal, and N. Pederson. 1997. Effects of canopy structure on resource availability and seedling responses in a longleaf pine ecosystem. Canadian Journal of Forest Research 27:1458-1464.

Palik, B. J., R. J. Mitchell, S. Pecot, M. Battaglia, and P. Mou. 2003. Spatial distribution of overstory retention influences resource availability and seedling growth: a silvicultural experiment using longleaf pine. Ecological Applications 13:674-686.

Peck, J. E., E. K. Zenner, and B. Palik. 2012. Variation in microclimate and early growth of planted pines under dispersed and aggregated overstory retention in mature managed red pine in Minnesota. Canadian Journal of Forest Research 42:279-290.

Perala, D. A., and D. Alban. 1993. Allometric biomass estimators for aspen-dominated ecosystems in the upper
Great Lakes. USDA Forest Service Research Paper NC-314. USDA Forest Service, North Central Research Station, Saint Paul, Minnesota, USA.

Perry, M. A., R. J. Mitchell, B. R. Zutter, G. R. Glover, and D. H. Gjerstad. 1993. Competitive responses of loblolly pine to gradients in loblolly pine, sweetgum, and broomsedge densities. Canadian Journal of Forestry Research 10:2049 2058.

Pitt, D. G., A. E. Morneault, P. Bunce, and F. W. Bell. 2000. Five years of vegetation succession following vegetation management treatments in a jack pine ecosystem. Northern Journal of Applied Forestry 17:100-109.

Powers, M. D., K. S. Pregitzer, and B. J. Palik. 2008. Physiological performance of three pine species provides evidence for gap partitioning. Forest Ecology and Management 256:2127-2135.

Powers, M. D., K. S. Pregitzer, B. J. Palik, and C. R. Webster. $2009 a$. Water relations of pine seedlings in contrasting overstory environments. Forest Ecology and Management 258:1442-1448.

Powers, M. D., K. S. Pregitzer, B. J. Palik, and C. R. Webster. 2010 . Wood $\delta 13 \mathrm{C}, \delta 18 \mathrm{O}$ and radial growth responses of residual red pine to variable retention harvesting. Tree Physiology 30:326-334.

Powers, M. D., K. S. Pregitzer, B. J. Palik, and C. Webster. 2011. The physiological basis for regeneration response to variable retention harvest treatments in three pine species. Forestry 84:13-22.

Powers, M. D., C. R. Webster, K. S. Pregitzer, and B. J. Palik. $2009 \mathrm{~b}$. Spatial dynamics of radial growth and efficiency in residual Pinus resinosa following aggregated retention harvesting. Canadian Journal of Forest Research 39:109-117.

Rose, C. R., and P. S. Muir. 1997. Green-tree retention: consequences for timber production in forests of the western Cascades, Oregon. Ecological Applications 7:209-217.

Sands, B. A., and M. D. Abrams. 2011. A 183-year history of fire and recent fire suppression impacts in select pine and oak forest stands of the Menominee Indian Reservation, Wisconsin. American Midland Naturalist 166:325-338.

Scott, R. E., M. G. Neyland, and D. J. McElwee. 2013. Early regeneration results following aggregated retention harvesting of wet eucalypt forests in Tasmania, Australia. Forest Ecology and Management 302:354-363.

Swanson, M. E., J. F. Franklin, R. L. Beschta, C. M. Crisafulli, D. A. DellaSala, R. L. Hutto, D. B. Lindenmayer, and F. J. Swanson. 2011. The forgotten stage of forest succession: early-successional ecosystems on forest sites. Frontiers in Ecology and the Environment 9:117-125.

Tesch, S. D., and E. J. Korpela. 1993. Douglas-fir and white fir advance regeneration for renewal of mixed conifer forests. Canadian Journal of Forest Research 23:1427-1437.

Urgenson, L. S., C. B. Halpern, and P. D. Anderson. 2013. 12year responses of planted and naturally regenerating conifers to variable-retention harvest in the Pacific Northwest, U.S.A. Canadian Journal of Forest Research 43:46-55.

Weber, M. G., R. S. McAlpine, B. M. Wotton, J. G. Donnelly, and M. W. Hobbs. 1995. Prescribed burning and disk trenching effects on early plantation performance in eastern Ontario, Canada. Forest Ecology and Management 78:159 171.

Weyenberg, S., L. E. Frelich, and P. B. Reich. 2004. Logging versus fire: how does disturbance type influence the abundance of Pinus strobus regeneration. Silva Fennica 38:179-194.

Zenner, E. K., S. A. Acker, and W. H. Emmingham. 1998. Growth reduction in harvest-age, coniferous forests with residual trees in the western central Cascade Range of Oregon. Forest Ecology and Management 102:75-88. 